\title{
A Pilot Study To Evaluate The Effect Of A Novel Calcium And Vitamin D-Containing Oral Bolus On Serum Calcium Levels In Holstein Dairy Cows Following Parturition
}

This article was published in the following Dove Press journal:

Veterinary Medicine: Research and Reports

\section{Daniel A Shock (iD) \\ Steven M Roche' \\ Rachel Genore ${ }^{1,2}$ \\ Merle E Olson (iD) ${ }^{3}$}

'Agricultural Communications and Epidemiological Research (ACER)

Consulting, Guelph, Ontario, Canada;

${ }^{2}$ Heartland Veterinary Services, Listowel,

Ontario, Canada; ${ }^{3}$ Solvet Animal Health,

Calgary, Alberta, Canada
Correspondence: Daniel A Shock Agricultural Communications and Epidemiological Research (ACER) Consulting, 100 Stone Road West, Unit I03A, Guelph, Ontario NIG 5L3, Canada $\mathrm{Tel}+\mathrm{I}-519-362-1 \mid 142$

Email dshock@acerconsult.ca

\begin{abstract}
Background: The initiation of lactation challenges the ability of the modern lactating cow to maintain calcium homeostasis, and typically results in a drop in blood calcium levels, leading to mobilization of calcium reserves from skeletal stores. As such, the recommendation to provide supplemental calcium at parturition to older cows has become an industrystandard practice.

Methods: Mature cows were treated at calving and $12 \mathrm{hrs}$ later with either the novel calcium bolus (NB) or a commercially available calcium bolus (CB). Blood was collected from animals at $0,1,6,12,13$, and 24 hrs following calving, and the resulting serum samples were analyzed.
\end{abstract}

Results: Overall, there was no statistical difference between the NB and CB groups for blood calcium levels within the first $24 \mathrm{hrs}$ following parturition $(\mathrm{P}=0.50)$. Cows in both groups experienced a significant increase in serum calcium by $1 \mathrm{hr}$ after parturition; however, this increase was not sustained through subsequent sampling times.

Conclusion: This pilot study demonstrates that both boluses have a similar effect in the elevation of blood calcium.

Keywords: hypocalcemia, milk fever, calcium supplementation, parturition, dairy cow

\section{Introduction}

The initiation of milk production challenges the ability of the lactating dairy cow to maintain normal calcium concentrations. Once lactation begins, blood calcium levels drop leading to mobilization of calcium reserves from skeletal stores. ${ }^{1,2}$ Clinical and subclinical hypocalcaemia are common issues in the dairy industry, ${ }^{3-5}$ and both are associated with a variety of negative sequelae including an increased risk of displaced abomasum, mastitis, retained placenta, dystocia, and ketosis. ${ }^{6,7}$ Given these negative connotations, it is imperative to improve the calcium status of a newly freshened dairy cow.

Oral supplementation with calcium chloride and calcium sulfate in a fat-coated bolus has been shown to have significant effects on improving calcium status in the period following calving. ${ }^{8}$ Clinically, Oetzel and Miller ${ }^{9}$ found that the administration of the oral bolus to lame and high-producing cows leads to fewer health events and higher milk production in those groups. ${ }^{9}$ This would lead to an economic benefit of $\$ 3$ to $\$ 8$ per cow in these circumstances. ${ }^{10}$ Another study comparing 
intravenous (IV) and oral calcium supplementation found that, while IV calcium led to earlier and higher peak serum calcium levels, oral calcium supplementation was associated with higher serum calcium between 20 and $48 \mathrm{hrs}$ post-treatment. ${ }^{11}$ Further, treatment with a calcium-containing bolus post calving was associated with a lower incidence of subclinical hypocalcemia, improved pregnancies per breeding, shorter days to pregnancy, and higher milk production in multiparous cows. ${ }^{12-14}$ Other researchers have found equivocal effects of oral calcium supplementation on serum calcium, health, and reproductive outcomes. ${ }^{15}$

There has been a very strong adoption of the oral calcium supplement by dairy producers throughout North America; however, many of the alternative products to this product have not been tested to demonstrate similar efficacy in influencing blood calcium levels.

Therefore, the primary objective of this pilot study was to assess the ability of a novel oral calcium bolus containing calcium chloride, calcium sulfate, and vitamin D3 to influence the serum calcium level in recently fresh, mature Holsteins over the first 24 hrs following parturition, relative to a positive control. We hypothesized that there would be no difference between the two oral boluses with respect to serum calcium levels over the first $24 \mathrm{hrs}$ following administration.

\section{Materials And Methods \\ Ethics Statement}

The present field-based study was conducted in compliance with the research guidelines set forth by the Canadian Council on Animal Care after appropriate Animal Use Protocol review by the Institutional Animal Care and Use Committee (Alberta Agriculture, Airdrie Alberta, Canada).

\section{Sample Size Calculation}

Based on the previous research, oral calcium supplementation should increase the serum calcium concentration by $0.25 \mathrm{mmol} / \mathrm{L}(0.125 \mathrm{mmol} / \mathrm{L}$ standard deviation) relative to levels at calving. ${ }^{15} \mathrm{~A}$ total sample size of 20 mature cows -10 each in the novel bolus (NB, $579.1 \mathrm{mg} / \mathrm{g}$ calcium chloride, $231.6 \mathrm{mg} / \mathrm{g}$ calcium sulfate, and 50,000 IU vitamin D3; Calboost, Solvet, Calgary, Alberta, Canada) and commercially available bolus (CB, containing $579.1 \mathrm{mg} / \mathrm{g}$ calcium chloride, $231.6 \mathrm{mg} / \mathrm{g}$ calcium sulfate; Bovikalc, Boehringer Ingelheim Vetmedica Inc.,
St. Joseph, MO, USA) groups - was calculated, assuming a $95 \%$ confidence level and $80 \%$ power.

\section{Study Herd And Treatment Protocols}

The study was conducted at a commercial dairy farm milking 500 cows in southwestern Ontario, Canada, between March and September 2018. The average daily milk production per cow was $38 \mathrm{~kg}$, at $3.9 \%$ fat and $3.1 \%$ protein. The herd averaged 155 days in milk. The dry cow ration contained straw, corn silage, and protein supplement, and is considered low calcium, low phosphorous, low potassium, high magnesium diet that did not contain anionic salts. Historically, the farm averaged less than 5\% incident risk of clinical hypocalcemia. This farm was chosen for proximity to the veterinary clinic that assisted with sample handling and analysis, as well as the technical capability to collect and record relevant samples and data.

Cows were randomly allocated to receive either the NB or $\mathrm{CB}$ according to a randomization sheet that was generated using the RAND command in Microsoft Excel. In this experiment, a positive control was used, as the practice of oral calcium supplementation at calving is an industry-standard recommendation, and few producers capable of conducting field-based research are willing to accept the risk of not prophylactically treating all mature cows with oral calcium. First lactation cows and those animals whose calvings were unobserved were excluded from enrollment. The farm staff was responsible for bolus administration, blood sample collection and storage, and reporting any disease events. They were blinded to the treatment groups throughout the trial.

The bolus was given orally at calving and again at 12-hrs post-calving. Blood samples were collected via venipuncture of the coccygeal vein. A single vial of approximately $10 \mathrm{~mL}$ of blood was taken at $0,1,6,12$, 13, and 24 hrs relative to calving. Due to the practicalities associated with sampling enrolled cows, the sampling window could vary by $\pm 1 \mathrm{hr}$ of the protocol designation. Samples were allowed to clot, centrifuged for 5 mins at $800 \mathrm{x} \mathrm{g}$, and serum was transferred into sterile storage vials. The vials were stored at $-20^{\circ} \mathrm{C}$ until submitted for analysis. Samples were analyzed to determine total serum calcium, phosphorus, and magnesium via a photometric method (Abaxis Vetscan vs2, Abaxis Inc., Union City, CA, USA). Only one measurement was made per sample.

Following treatments, participating farm personnel were instructed to record treatment assignment and all pertinent health and disease events (including death and culling) for all cows that had calved after study commencement. 


\section{Data Collection}

Variables of interest for analysis included date and time of calving, calcium bolus administration, and blood collection, lactation number, dystocia, non-lactating days prior to calving, disease dates, culling/death dates, and occurrence of twin pregnancies. All results were transcribed into Excel (Microsoft Corporation, 2010, Redmond, WA, USA).

\section{Statistical Analysis}

All datasets were imported as comma-separated files into the Stata 14 (StataCorp LP, College Station, TX, USA) statistical software program for analysis. The cow was considered the unit of analysis for this study.

\section{Descriptive Statistics And Univariable Analysis}

Descriptive statistics were generated for the final dataset. Serum calcium, phosphorous, and magnesium levels were explored through graphical plots. Specific comparisons between the serum calcium, days dry, lactation, season of sampling, and the presence of twins at calving in NB and CB cows were made, with univariable statistical comparisons made using Fisher exact tests or Kruskal-Wallis oneway analysis of variance.

Statistical comparisons were made between potential predictor variables and outcomes of interest. For this study, the outcome of interest was serum calcium level (in $\mathrm{mmol} / \mathrm{L}$ ). Univariable linear regression modelling was employed to study variables of interest. Variables explored for each model included: treatment group (NB vs $\mathrm{CB}$ ), lactation group (2 and over 3 ), non-lactating days prior to parturition, season of calving, sampling time $(0,1,6,12,13$, and 24 hrs relative to calving), dystocia $(0=$ eutotic calving, $1=$ dystotic calving), and presence of twins at calving. Variables that had moderate statistical associations with the outcome of interest (defined at a liberal P-value $<0.2$ ) were included in subsequent multivariable models.

\section{Multivariable Regression Analysis}

A repeated-measures mixed-linear regression model was constructed, using random effects to model sample number within the cow, using a first-order autoregressive correlation structure between time points.

A step-wise backwards elimination process was employed, where variables identified as potentially associated with the outcome of interest in the initial univariable screening were included in a full multivariable model. Those variables having P-values for partial F-tests or type III tests of fixed effects greater than 0.05 were eliminated from the model after assessing whether they were part of biologically plausible interaction terms or had a confounding effect on the outcome of interest (eg, a $>20 \%$ change in coefficient values when the term is removed from the model). Continuous variables were assessed for linearity with predicted model outcomes through visually inspecting a LOWESS curve (local weight scatterplot smoothing) for a linear relationship, as well as the significance $(\mathrm{P}<0.05)$ of a quadratic term in the model. If a continuous variable did not have a linear relationship with the outcome of interest, it was subsequently categorized based on biologically relevant cut-points, or if appropriate, a quadratic term was retained in the model. Variables retained in the final model were assessed for collinearity through the examination of Pearson or Spearman rank-order correlation coefficients. When a high correlation was found between variables $(>0.6)$, the most biologically appropriate variable was chosen for inclusion in the final model. Standardized residuals were generated and visually assessed for normality and homoscedasticity for the linear mixed regression model. If the residuals were heteroskedastic or not normally distributed, appropriate transformations were performed on the outcome of interest.

\section{Results And Discussion}

Table 1 outlines the descriptive characteristics of trial animals. The CB group had a lower absolute number of animals in their second and third lactation, although this difference was not statistically significant. The twinning rate in each group was relatively low, with two twin calvings in the $\mathrm{CB}$ group and one in the NB group. Cows in both groups remained clinically healthy throughout the duration of the study. Mean non-lactating days were numerically greater for NB cows, but this difference was not statistically significant. Days dry and its quadratic function were included in the final linear model, as it was significantly associated with serum calcium (Table 2) and had a confounding influence noted on the coefficients for treatment.

Figure 1A outlines a descriptive comparison of serum calcium levels between NB and CB-treated animals. Of note, NB cows had lower serum calcium at parturition relative to $\mathrm{CB}$ animals, but the NB group had numerically higher serum calcium levels in subsequent sampling times (Figure 1A). Figure 1(B and C) outlines raw mean (SD) serum phosphorus and magnesium levels measured in study cows, respectively. There were no significant differences between NB and CB groups for all blood metabolites $(\mathrm{P}>0.05)$ measured on univariable analysis. 
Table I Descriptive Demographic Comparisons Between A Novel Calcium Bolus (NB) And A Commercially Available Bolus (CB) Of Cows Enrolled On A Commercial Dairy Farm In Southwestern Ontario, Canada

\begin{tabular}{|l|l|l|l|}
\hline Variable & NB & CB & P-Value \\
\hline Lactation (frequency) & & & \\
2nd and 3rd lactation & 5 & 7 & 0.65 \\
$>$ 3rd lactation & 5 & 3 & \\
\hline Calving Season (frequency) & & & \\
$\quad$ March-April & 3 & 1 & 0.41 \\
May-July & 1 & 3 & \\
August-September & 6 & 6 & \\
\hline Twins (frequency) & & & \\
Yes & 1 & 2 & 1.00 \\
No & 9 & 8 & \\
\hline Mean Days Dry (standard error) & $73.2(8.1)$ & $61.3(6.3)$ & 0.23 \\
\hline
\end{tabular}

Of note, there were 2 animals of 20 that were sampled slightly outside of the appropriate window (time $\pm 1 \mathrm{hr}$ ) as outlined in the study protocol for the 12-hrs samples, both of which were in the NB treatment group. Analyses were conducted both including and excluding these animals, with no bearing on the outcome of the experiment.
Therefore, the data for these animals remained in the analysis $(\mathrm{N}=20)$ to avoid excessive model overfitting.

Residual analysis from raw serum calcium data showed considerable heteroskedasticity; therefore, natural logarithms were calculated for each calcium value. Upon subsequent iterations of the model, residuals were homoscedastic and normally distributed with this transformation. Multivariable, repeated-measures linear regression model output is given in Table 2 .

Serum calcium levels did not differ at any point between CB- and NB-treated cows $(\mathrm{P}=0.50)$. Serum calcium levels rose dramatically at the $1 \mathrm{hr}$ mark following parturition; however, these levels subsequently dropped and were not significantly different from baseline $(t=0)$ levels for the remainder of the 24-hrs sampling period. Cows that calved in the months of August and September had significantly higher serum calcium levels $(P=0.002)$ relative to cows calving in March and April. Older cows tended $(\mathrm{P}=0.11)$ to have lower serum calcium levels. This variable was included in the model, as it had a significant confounding effect $(>20 \%$ change in coefficient value) on the treatment variable of interest (NB versus CB-treatment). Previous research has

Table 2 Multivariable, Repeated Measures Linear Regression Model Output Evaluating The Effect That The Novel Bolus (NB) Relative To The Commercially Available Bolus (CB) Has On Log-Transformed Serum Calcium Values Within The First 24 hrs Following Parturition

\begin{tabular}{|c|c|c|c|c|c|}
\hline \multirow[b]{2}{*}{ Treatment } & \multirow[t]{2}{*}{ Coefficient } & \multirow[t]{2}{*}{ Standard Error } & \multirow[t]{3}{*}{ P-Value } & \multicolumn{2}{|c|}{ 95\% Confidence Interva } \\
\hline & & & & & \\
\hline $\mathrm{CB}$ & Referent & & & & \\
\hline NB & 0.03 & 0.05 & 0.50 & -0.06 & 0.12 \\
\hline \multicolumn{6}{|c|}{ Sample Time (h relative to parturition) } \\
\hline 0 & Referent & & & & \\
\hline 1 & 0.18 & 0.05 & 0.001 & 0.08 & 0.29 \\
\hline 6 & 0.07 & 0.06 & 0.23 & -0.04 & 0.18 \\
\hline 12 & 0.04 & 0.06 & 0.52 & -0.08 & 0.15 \\
\hline 13 & 0.01 & 0.06 & 0.80 & -0.10 & 0.13 \\
\hline 24 & -0.01 & 0.06 & 0.82 & -0.13 & 0.10 \\
\hline \multicolumn{6}{|l|}{ Calving Month } \\
\hline March-April & Referent & & & & \\
\hline May-July & -0.04 & 0.07 & 0.54 & -0.17 & 0.09 \\
\hline August-September & 0.16 & 0.05 & 0.002 & 0.06 & 0.27 \\
\hline Days Dry & 0.01 & 0.00 & $<0.001$ & 0.01 & 0.02 \\
\hline Days Dry (quadratic) & 0.00007 & 0.00002 & 0.001 & 0.00 & 0.00 \\
\hline \multicolumn{6}{|l|}{ Cow Lactation: } \\
\hline 2nd and 3rd & Referent & & & & \\
\hline $3 r d+$ & -0.08 & 0.05 & 0.11 & -0.17 & 0.02 \\
\hline Constant & -0.07 & 0.15 & 0.65 & -0.36 & 0.23 \\
\hline
\end{tabular}



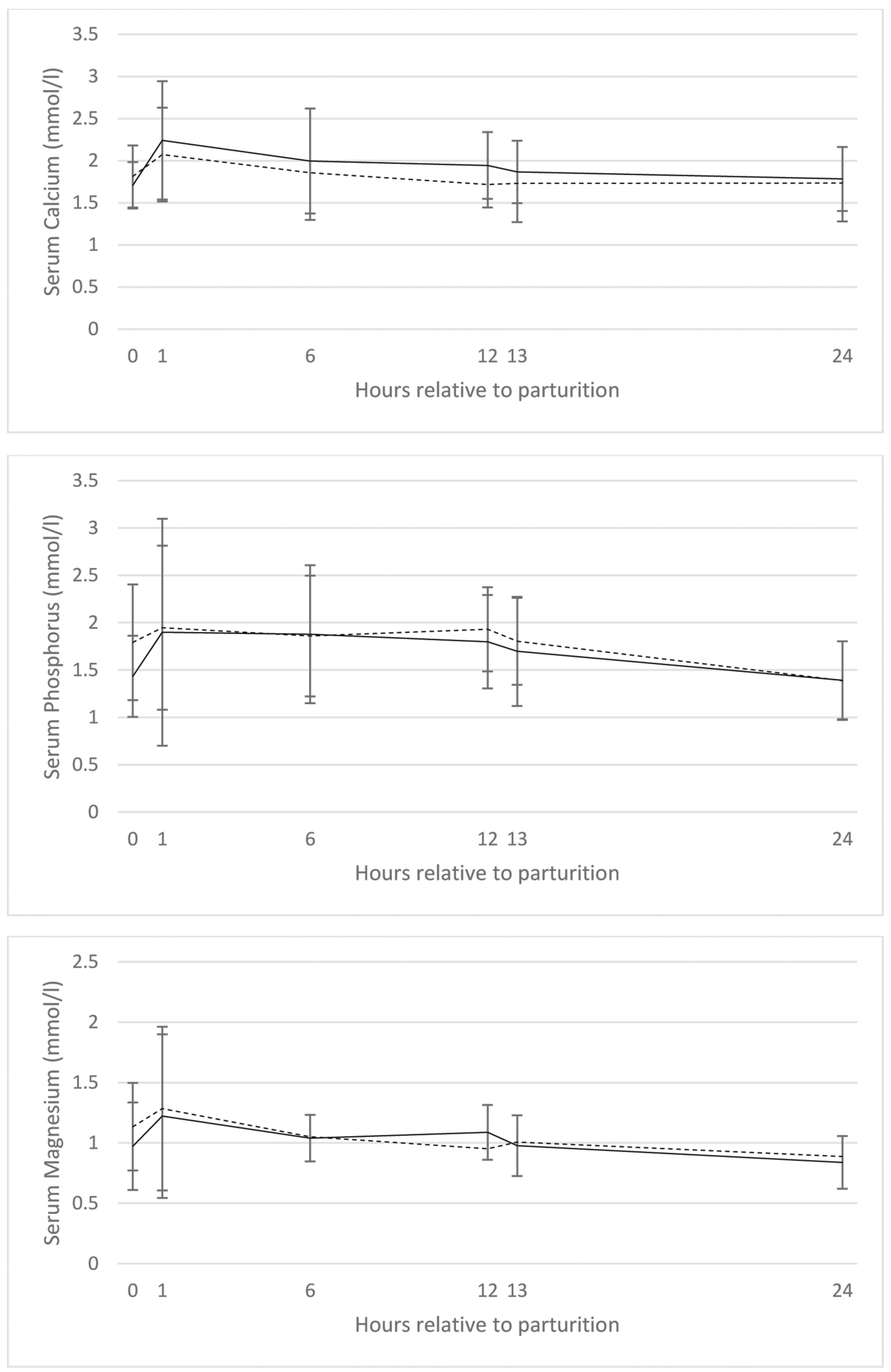

Figure I (Top) Raw mean (standard deviation) serum calcium (mmol/L) plot of novel calcium bolus (solid line) and commercially available bolus (dashed line) treatment groups over the first 24 hrs following parturition. (Middle) Raw mean (standard deviation) serum phosphorus (mmol/L) plot of novel calcium bolus (solid line) and commercially available bolus (dashed line) treatment groups over the first 24 hrs following parturition. (Bottom) Raw mean (standard deviation) serum magnesium (mmol/L) plot of novel calcium bolus (solid line) and commercially available bolus (dashed line) treatment groups over the first 24 hrs following parturition. 
noted older cows to be at an increased risk of clinical milk fever. $^{1}$

Calcium supplementation of cows around parturition has been studied extensively for the treatment and prevention of hypocalcemia. ${ }^{1,2,9,12,15,16}$ Subclinical hypocalcemia (serum calcium levels $<2.0 \mathrm{mmol} / \mathrm{l}$ ) is a pervasive issue in the modern dairy industry. All cows in the current study experienced subclinical hypocalcemia. Previous research has found that the incidence to be approximately $50 \%$ in mature (2nd or greater lactation) Holstein cows. ${ }^{4,17}$ Indeed, the risk of displaced abomasum, ketosis, retained placenta, and metritis were 3.7, 5.5, 3.4, and 4.3 times more likely, respectively, in cows that experience subclinical hypocalcemia relative to normocalcemic cohorts. ${ }^{18}$ Overall, the costs associated with subclinical hypocalcemia are estimated to be approximately $\$ 125$ per case. ${ }^{2}$ For the average 500 cow herd, assuming $65 \%$ of the herd is in their second lactation or greater, and a $50 \%$ incidence of subclinical mastitis, the cost would be approximately $\$ 20,312.50$. Clearly, significant efforts should be made to prevent such losses.

Cows that received both calcium supplements experienced significant increases in serum calcium levels; however, these levels were not sustained for the remainder of the $24 \mathrm{hrs}$ following parturition. There has been extensive research into the provision of supplemental calcium to cattle around parturition. ${ }^{2,9,12,15-17}$ Early studies by Goff and $\mathrm{Horst}^{16}$ found that cows supplemented with $128.8 \mathrm{~g}$ of calcium chloride as an oral drench experienced significant elevations in serum calcium up to $6 \mathrm{hrs}$ following treatment. Interestingly, the authors noted that stimulating the esophageal groove with vasopressin prior to calcium administration resulted in higher serum calcium concentrations than calcium chloride supplementation alone. ${ }^{16}$ This rumen bypassing effect could improve overall calcium absorption and potentially explain the variable influence that solid boluses have on serum calcium concentration, despite having significantly higher calcium chloride levels relative to liquid products tested. ${ }^{19}$

Over and above the transient effects of supplemental calcium, the acidifying nature of the calcium chloride and calcium sulfate could influence systemic $\mathrm{pH},{ }^{16,20}$ as the feeding of anionic diets to transition cows is a proven strategy to reduce the incidence of hypocalcemia. ${ }^{21}$

These results are consistent with a recent study that found oral calcium supplementation effectively increased serum calcium levels at the 1 -hr and 24-hrs postpartum relative to untreated controls. ${ }^{8,15}$ One important difference between the current experiment and the cited studies was the use of negative control animals. As the current study was a pilot field-based trial, and calcium supplementation is a pervasive practice throughout the industry, it was difficult to recruit a suitable herd capable of an intensive sampling schedule that would allow cows at high risk for hypocalcemia to remain untreated. On the other hand, numerous studies evaluating postpartum, serial serum calcium levels in cows not receiving supplemental calcium either remain constant or significantly decrease relative to baseline levels at calving. ${ }^{8,13,15,20,22}$ Given the lack of a concurrent negative control, no definitive conclusions can be made.

The addition of vitamin D3 to the NB has the theoretical advantage of improving plasma $\mathrm{Ca}$ and $\mathrm{P}$ concentrations through intestinal absorption and bone resorption. ${ }^{23}$ Though supplementation with exogenous vitamin D has significantly affected serum Vitamin D levels, ${ }^{23}$ the effects on serum calcium levels have been variable. ${ }^{24-26}$ The cited studies used higher amounts of vitamin $\mathrm{D}^{24-26}$ and included them in the diets of transition cows. ${ }^{25,26}$ To this author's knowledge, the effects of bolus supplementation of 50,000 IU vitamin D3 have not been studied, and the utility of inclusion in commercial preparations is unknown.

The manufacturing and marketing of novel supplements (ie, mineral boluses, vitamins, botanicals) are not subjected to as rigorous a regulatory process relative to veterinary pharmaceutical products. As such, there is a paucity of peer-reviewed literature evaluating such novel products in the field. The present pilot study does display that the novel product is able to cause an elevation in serum calcium of recently calved cows of a magnitude like another commercially available, efficacious product of similar composition.

\section{Conclusion}

Subclinical hypocalcemia is a prevalent disorder of the modern commercial dairy cow. The current pilot study found oral supplementation with two commercially available calcium boluses was associated with a significant increase in serum calcium levels at $1-\mathrm{hr}$ post-calving. Producers and veterinarians wishing to affect a sustained serum calcium response in fresh cows should not rely on calcium boluses and instead focus on preventative management and nutritional practices. 


\section{Acknowledgments}

The authors would like to thank Dr. Ray Reynen (Attending veterinarian from Heartland Veterinary Services) and the participating farm and its workers whose hard work made this trial possible.

\section{Disclosure}

The project was wholly funded by the sponsor, Solvet Inc. (Calgary, Alberta, Canada). DS, SR, RR, and RG received financial support from the sponsor for conducting the study, analyzing the data, and preparing the manuscript. MO is an employee of the sponsor. The authors have no other conflicts of interest to report.

\section{References}

1. Goff JP. The monitoring, prevention, and treatment of milk fever and subclinical hypocalcemia in dairy cows. Vet $J$. 2008;176(1):50-57. doi:10.1016/j.tvj1.2007.12.020

2. Oetzel GR. Oral calcium supplementation in peripartum dairy cows. Vet Clin North Am - Food Anim Pract. 2013;29(2):447-455. doi:10. 1016/j.cvfa.2013.03.006

3. DeGaris PJ, Lean IJ. Milk fever in dairy cows: a review of pathophysiology and control principles. Vet J. 2008;176(1):58-69. doi:10. 1016/j.tvj1.2007.12.029

4. Reinhardt TA, Lippolis JD, McCluskey BJ, Goff JP, Horst RL. Prevalence of subclinical hypocalcemia in dairy herds. Vet $J$. 2011;188(1):122-124. doi:10.1016/j.tvj1.2010.03.025

5. McLaren CJ, Lissemore KD, Duffield TF, Leslie KE, Kelton DF, Grexton B. The relationship between herd level disease incidence and a return over feed index in Ontario dairy herds. Can Vet J. 2006;47 (8):767-773.

6. Curtis CR, Erb HN, Sniffen CJ, et al. Association of parturient hypocalcemia with eight periparturient disorders in Holstein cows. $J$ Am Vet Med Assoc. 1983;183(5):559-561.

7. Seifi HA, LeBlanc SJ, Leslie KE, Duffield TF. Metabolic predictors of post-partum disease and culling risk in dairy cattle. Vet J. 2011;188 (2):216-220. doi:10.1016/j.tvj1.2010.04.007

8. Sampson JD, Spain JN, Jones C, Carstensen L. Effects of calcium chloride and calcium sulfate in an oral bolus given as a supplement to postpartum dairy cows. Vet Ther. 2009;10(3):131-139.

9. Oetzel GR, Miller BE. Effect of oral calcium bolus supplementation on early-lactation health and milk yield in commercial dairy herds. $J$ Dairy Sci. 2012;95(12):7051-7065. doi:10.3168/jds.2012-5510

10. McArt JAA, Oetzel GR. A stochastic estimate of the economic impact of oral calcium supplementation in postparturient dairy cows. J Dairy Sci. 2015;98(10):7408-7418. doi:10.3168/jds.2015-9479

11. Blanc CD, Van der List M, Aly SS, Rossow HA, Silva-del-Río N. Blood calcium dynamics after prophylactic treatment of subclinical hypocalcemia with oral or intravenous calcium. J Dairy Sci. 2014;97 (11):6901-6906. doi:10.3168/jds.2014-7927
12. Martinez N, Sinedino LDP, Bisinotto RS, et al. Effects of oral calcium supplementation on mineral and acid-base status, energy metabolites, and health of postpartum dairy cows. J Dairy Sci. 2016;99(10):8397-8416. doi:10.3168/jds.2015-10527

13. Martinez N, Sinedino LDP, Bisinotto RS, et al. Effects of oral calcium supplementation on productive and reproductive performance in Holstein cows. J Dairy Sci. 2016;99(10):8417-8430. doi:10.3168/jds.2015-10529

14. Leno BM, Neves RC, Louge IM, et al. Differential effects of a single dose of oral calcium based on postpartum plasma calcium concentration in Holstein cows. J Dairy Sci. 2018;101(4):3285-3302. doi: $10.3168 /$ jds.2017-13164

15. Domino AR, Korzec HC, McArt JAA. Field trial of 2 calcium supplements on early lactation health and production in multiparous Holstein cows. J Dairy Sci. 2017;100(12):9681-9690. doi:10.3168/ jds.2017-12885

16. Goff JP, Horst RL. Oral administration of calcium salts for treatment of hypocalcemia in cattle. J Dairy Sci. 1993;76(1):101-108. doi:10.3168/jds.S0022-0302(93)77328-2

17. Horst RL, Goff JP, Reinhardt TA. Role of vitamin D in calcium homeostasis and its use in prevention of bovine periparturient paresis. Acta Vet Scand Suppl. 2003;97:35-50.

18. Rodríguez EM, Arís A, Bach A. Associations between subclinical hypocalcemia and postparturient diseases in dairy cows. J Dairy Sci. 2017;100(9):7427-7434. doi:10.3168/jds.2016-12210

19. Thilsing-Hansen T, Jørgensen RJ, Østergaard S. Milk fever control principles: a review. Acta Vet Scand. 2002;43(1):1-19. doi:10.1186/ 1751-0147-43-1

20. Roberts K, Bennison J, McDougall S. Effect of treatment with oral $\mathrm{Ca}$ boluses following calving on concentrations of $\mathrm{Ca}$ in serum in pasture-based dairy cows. N Z Vet J. 2019;67(1):1-7. doi:10.1080/ 00480169.2018.1520654

21. Lean IJ, Santos JEP, Block E, Golder HM. Effects of prepartum dietary cation-anion difference intake on production and health of dairy cows: a meta-analysis. J Dairy Sci. 2018;102(3):2103-2133. doi:10.3168/jds.2018-14769

22. Miltenburg CL, Duffield TF, Bienzle D, Scholtz EL, LeBlanc SJ. Randomized clinical trial of a calcium supplement for improvement of health in dairy cows in early lactation. J Dairy Sci. 2016;99 (8):6550-6562. doi:10.3168/jds.2016-10961

23. McGrath JJ, Savage DB, Godwin IR. The potential for pharmacological supply of 25-hydroxyvitamin D to increase phosphorus utilisation in cattle. Anim Prod Sci. 2013;53(11):1238. doi:10.1071/AN13193

24. Taylor MS, Knowlton KF, McGilliard ML, Seymour WM, Herbein JH. Blood mineral, hormone, and osteocalcin responses of multiparous jersey cows to an oral dose of 25-hydroxyvitamin D3 or vitamin D3 before parturition. J Dairy Sci. 2008;91(6):2408-2416. doi:10. 3168/jds.2007-0750

25. Wilkens MR, Oberheide I, Schröder B, Azem E, Steinberg W, Breves $\mathrm{G}$. Influence of the combination of 25-hydroxyvitamin D3 and a diet negative in cation-anion difference on peripartal calcium homeostasis of dairy cows. J Dairy Sci. 2011;95(1):151-164. doi:10.3168/jds. 2011-4342

26. Rodney RM, Martinez N, Block E, et al. Effects of prepartum dietary cation-anion difference and source of vitamin D in dairy cows: vitamin D, mineral, and bone metabolism. J Dairy Sci. 2017;101 (3):2519-2543. doi:10.3168/jds.2017-13737 


\section{Publish your work in this journal}

Veterinary Medicine: Research and Reports is an international, peerreviewed, open access journal publishing original research, case reports, editorials, reviews and commentaries on all areas of veterinary medicine. The manuscript management system is completely online and includes a very quick and fair peer-review system. Visit http://www.dovepress.com/testimonials.php to read real quotes from published authors.

Submit your manuscript here: http://www.dovepress.com/veterinary-medicine-research-and-reports-journal 